\title{
The importance of child wellbeing
}

\author{
Susannah Stevens · Aaron Jarden
}

\section{Introduction}

This special edition on child wellbeing, a joint venture between the International Journal of Wellbeing and the University of Canterbury Child Well-being Research Institute, is timely. The current global political climate is saturated with many socio-economic and environmental challenges that are concomitant with wellbeing; many directly concerning our future generations. Topics such as environmental sustainability, systemic injustices and various inequality are being scrutinized by all ages and professions, to ensure that policy and practice are aligned when it comes to wellbeing. On September 2018, the Third International Conference on Wellbeing and Public Policy was held in Wellington, New Zealand; sending a clear message that wellbeing and policy were not considered dichotomous when it came to societal progression in New Zealand. The Wellbeing Budget 2019 (New Zealand Treasury, 2019) was released shortly after in May 2019. New Zealand is not alone, as many countries are broadening their definitions to what constitutes societal growth and success (Scotland and Iceland also prime examples); and this has allowed more room for wellbeing dialogue. The notion of the necessity of wellbeing to live a fulfilling and flourishing life is not at all novel. Those familiar with philosophy, Eastern or Western, could easily recount many ancient authors and texts where wellbeing was at the heart of utopian participation in life throughout millennia. Even Epicurus, the misunderstood hedonist, prescribed that all additional pleasures if life relied on wellbeing first (Rosenbaum, 1990). What is novel however, is the growing empathy and urgency across many sectors and disciplines to better understand wellbeing, and identify the supporting role they can play in supporting and achieving wellbeing. There is a global shift towards valuing wellbeing in its own right, a desire for all human beings to live a good life, and to optimally thrive. Moreover, there is an increasing understanding by the State that wellbeing is isolated from access to education, human rights and social determinants of health. These trends can be seen in policy development and inclusion (e.g., Jarden, Jarden, \& Oades, 2017); an edict that wellbeing is here to stay. The Global Analysis of Well-being Report (Graham, Comin \& Anand, 2018) and the Global Happiness and Wellbeing Policy Report (Global Happiness Council, 2019) are two of the many examples of this advancement of global wellbeing policy documentation. This push for wellbeing policy coupled with the accountability for governments to measure wellbeing has seen a drive for a better understanding of wellbeing, and specifically what this might mean for all people, including our future generations, including children which have largely been left out of the dialogue to date. 
In 1989, the United Nations (UN) Convention on the Rights of the Child was ratified as a significant legislative act that prioritised the voices and worldly contributions of all children and youth (United Nations, 1989). The articles themselves within the document mandate human rights, needs and expression, nevertheless the common innate thread throughout the document is the importance of child wellbeing. More recently, in January 2016, Goal 3 of the global 17 Sustainable Development Goals (SDGs) affirmed the need for healthy lives and promotion of wellbeing at all ages (United Nations, 2015); increasing the urgency and need of a global mandated agenda that targets inter-generational societal change. However, despite this much needed shift in global acceptance and policy prioritisation, the UN recognises that it is ultimately the acceptance or resistance to what happens at the national, local and family levels that dictates success (United Nations, 2015). Therefore, wellbeing interventions or policy on wellbeing needs to be contextually appropriate and culturally responsive to understand and provide relevant support. Regardless of which dominant theoretical perspective of child and adolescent development is focused on, wellbeing is a fundamental measure when it comes to learning and growing as a human being. Cognitive development or processing is not void of the social and cultural context in which it occurs, and therefore to be 'well' or what constitutes 'wellbeing' as a young person will inevitably vary depending on life experience. A child in poverty or an affluent child of trauma will have different interpretations of what constitutes wellbeing compared to a child who is privileged to never experience such significant trauma or poverty. Children from different backgrounds and cultures will differ regarding how they perceive and experience wellbeing, as what constitutes success, happiness, respect, joy or independence will vary greatly. Moreover, much of these facets of wellbeing are relational, meaning the family unit and caregiving structure impacts significantly on the child's wellbeing. Indeed, the Convention on the Rights of the Child recognises the importance of the family as of fundamental importance for the growth and wellbeing of a child. Despite these differences, core similarities remain, such as the need for developmental experiences and encounters to learn. Both Piagetian and Vygotskian learning theories on social interaction mandate that a combination of adult-child interaction and peer interactions are necessary to learn and grow (McDevitt \& Ormrod, 2002). Children and youth can not only learn by passively consuming the surrounding environment and the knowledge of prior generations, but rather, they must also have the opportunities and empowerment to experiment and influence phenomena themselves. This is no different to a child learning about, understanding, and processing their own wellbeing. Therefore, to be effective, wellbeing intervention or policy should cover the individual child or youth needs and voice, alongside voice of a relational nature within the socio-economic context. If only one of these elements is considered, then the complexity of supporting or measuring a child's wellbeing cannot be fully comprehended, realised, or sustained. Questions such as 'what weight is given to child or youth voice in this decision-making process?' or 'which socio-cultural paradigm has shaped this wellbeing framework' could be asked across different sectors looking to better understand or measure wellbeing, especially when it comes to children and youth. There is strength in approaches that consider multi-paradigmatic methodologies or inter-professional responses.

The authors within this special edition focusing on child wellbeing do an admirable job of explicating the difficulties that exist as different sectors come to understand wellbeing from 
differing paradigms and traditions. The specific papers within this special edition explore diverse topics such as school-based interventions for wellbeing (Jessica Morse, Maeve O'Donnell, Arissa Walberg, Bryan Dik); positive psychology family interventions (Selja Pentti, Åse Fagerlund, Pär Nyström); early experiences that promote wellbeing in our young children (Tracy Gleason, Darcia Narvaez); adolescent conceptualisations of wellbeing (Gazal Bharara, Scott Duncan, Aaron Jarden, Erica Hinckson); well-being through the eyes of Samoan children (Emma DunlopBennett, Jenny Bryant-Tokalau, Anthony Dowell); and the idea of a cross-disciplinary framework for promoting youth wellbeing (Amanda Ng, Dianne Vella-Brodrick). The collective impact of these contributions is their desire to improve policy and practice around understanding and measuring child wellbeing. Each piece within this special edition contributes a varied discourse to the wellbeing debate; evidencing the continual need for transparency, discussion and praxis where ever 'child wellbeing' is concerned.

\section{Authors}

Susannah Stevens

University of Canterbury

susannah.stevens@canterbury.ac.nz

Aaron Jarden

University of Melbourne

\section{Publishing Timeline}

Received 14 August 2019

Accepted 23 September 2019

Published 30 September 2019

\section{References}

Global Happiness Council (GHC) (2019). Global Happiness and Wellbeing Policy Report. Retrieved from: http://www.happinesscouncil.org/report/2019/

Graham, C., Comin, F., \& Anand, P. (Eds.) (2018). The Global Analysis of Wellbeing Report. Oxford, Oxford Foundation for Knowledge Exchange. Retrieved from: http://globalwellbeingreport.org/wpcontent/uploads/2018/02/WellBeingGlobalReport.pdf

Jarden, R., Jarden, A, \& Oades, L. (2017). Wellbeing policy in Australia and New Zealand. In M. Slade, L. Oades, and A. Jarden (Eds.), Wellbeing, recovery and mental health, pp. 207-214. Cambridge University Press.

McDevitt, T. M., \& Ormrod, J. E. (2002). Child development and education. New Jersey: Pearson Education Inc

New Zealand Treasury. (2019). The Wellbeing Budget 2019. Retrieved from: http://www.treasury.govt.nz/publications/wellbeing-budget/wellbeing-budget-2019 ISBN 978-198-858042-5

Rosenbaum, S. E. (1990). Epicurus on pleasure and the complete life. The Monist; Hellenistic Ethics, 73(1) $22-41$.

The Department of the Prime Minister and Cabinet. (2019). Child and Youth Wellbeing Strategy. Retrieved from: https://childyouthwellbeing.govt.nz/resources/child-and-youth-wellbeing-strategy 
United Nations. (1989). Convention on the Rights of the Child. Retrieved from: https://www.ohchr.org/Documents/ProfessionalInterest/crc.pdf.

United Nations. (2015). Transforming our world: The 2030 Agenda for Sustainable Development A/RES/70/1. Retrieved from https://www.un.org/ga/search/view_doc.asp?symbol=A/RES/70/1 